$1-1-1981$

\title{
Teaching Physicians and Lawyers to Understand Each Other: The Development of a Law and Medicine Clinic
}

Robert L. Schwartz

University of New Mexico - School of Law

Follow this and additional works at: https://digitalrepository.unm.edu/law_facultyscholarship

Part of the Health Law and Policy Commons

\section{Recommended Citation}

Robert L. Schwartz, Teaching Physicians and Lawyers to Understand Each Other: The Development of a Law and Medicine Clinic, 2 The Journal of Legal Medicine 131 (1981).

Available at: https://digitalrepository.unm.edu/law_facultyscholarship/625

This Article is brought to you for free and open access by the UNM School of Law at UNM Digital Repository. It has been accepted for inclusion in Faculty Scholarship by an authorized administrator of UNM Digital Repository. For more information, please contact amywinter@unm.edu, Isloane@salud.unm.edu, sarahrk@unm.edu.

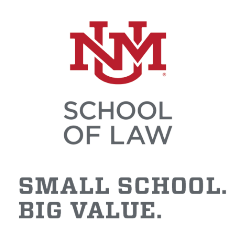

BIG VALUE. 


\section{Teaching Physicians and LAWYERS TO UNDERSTAND EACH OTHER}

\section{The Development of a Law and Medicine Clinic}

Robert L. Schwartz, J.D.*

\section{INTRODUCTION}

The chill in the relationship between the legal and medical professions reflects far more than the physician's perception of a medical malpractice insurance "crisis." The lack of understanding between the disciplines is really a consequence of the very different epistemologies of each profession. Physicians and lawyers view truth in different ways, and thus the professions solve problems in very different ways. To the lawyer, truth arises out of the conflict of ideas presented by adversaries. Truth depends upon the society and the place, and no proposition, however well articulated by whatever genius, is immune to challenge. For the physician, truth is a description of nature, necessarily true in all societies, and, at some point, no longer subject to challenge by reasonable people. These different professional epistemologies are manifested in, and perhaps created by, the very different professional educations provided to medical and law students. The didactic lecture and

- Associate Professor of Law, University of New Mexico; Postdoctoral Fellow, The Hastings Center Institute of Society, Ethics and Life Sciences. Address reprint requests to Professor Schwartz \% The Hastings Center, 360 Broadway, Hastings on Hudson, N.Y. 19706. 
clinical programs that make up the gist of a medical student's academic years are in sharp contrast to the Socratic courses almost universally employed to educate law students. Indeed, the process of professional education, as it exemplifies the ways in which the professions resolve problems, is as important in creating physicians and lawyers as is the substance of any particular course in which they might be enrolled.

Any attempt to teach law to medical students in the same way in which they are taught medical subjects will fail to teach medical students how lawyers reason and how they resolve problems. Similarly, any attempt to teach medicine to law students as if "law and medicine" were simply another substantive area of the law will leave attorneys unable to understand physicians' practice. One solution to this problem is to develop a combined law and medicine clinical program that could be added to the curricula of both the law and medical schools. Such a program would allow physicians and attorneys, working with each other on particular cases, to develop an understanding of both disciplines as well as an ability to recognize those areas in which they can be of assistance to each other.

\section{THE PROBLEM}

In an introduction to a symposium on legal education in medical schools, Dr. Merlin DuVal described the problem law schools and medical schools ought to be addressing:

When two lawyers get together in the lounge at the country courthouse-or when two physicians meet in the doctors' dressing room at 'the local hospital-you can usually expect that instant rapport will develop between them. But when you intermix these Perry Masons and Drs. Kildare, as often as not, you get self-consciousness-sometimes even defensiveness-springing up between them. Precisely why this occurs isn't clear. That it occurs at all is regrettable; after all, lawyers and physicians do not really compete with one another. On the contrary, the work of each may complement that of the other. One is concerned with relationships between men, while the other is concerned between men and their environment. ${ }^{1}$

That introduction was written almost a decade ago, before the eruption of what physicians have come to call the malpractice

1 DuVal, Editorial: Medical Schools Not Doing Good Job In Helping Students Understand Legal Profession, 46 J. Med. Educ. 387 (1971). 
crisis, and before state legislatures began reassessing the relationship between the professions. ${ }^{2}$ Now every state legislature has attempted to referee the fight between the medical and legal professions, ${ }^{3}$ and if defensiveness and self-consciousness were all that were to come out of a meeting between doctors and lawyers, it would be considered an unusually cordial affair.

In summarizing a course in law and medicine he offered to both law students and medical students, Dr. Martin Norton lamented that "the process of advocacy is completely foreign to the medical student, while the concepts of Aristotelian scientific deduction are apparently unknown to the law student." 4 The reasoning processes of the two professions are different, and the difference is in part the consequence of the basic facts with which they each begin, and the goal of their inquiry. In the classical model, the physician is confronted by a sick patient whom he must make well. His training tells him that he is capable of making the patient well, and his professional code of ethics tells him that such is his primary objective. The ultimate actor must be the physician, and, consequently, the ultimate treatment must be exactly that which he prescribes. Conversely, the attorney is an advocate. The ultimate determination is not in his hands, nor would he want it to be. His education trains him to make an argument on behalf of a proffered resolution to a dispute, and his canons of ethics prescribe that his primary obligation is to adequately present his position to some other decision maker. As long as physicians and attorneys do not understand their very different roles, even within their own establishments, they are unlikely to be able to understand each others' motivations and actions. ${ }^{s}$

2 The increase in medical malpractice insurance rates was apparent in the $1960 \mathrm{~s}$, but it was not until the middle of the last decade that this phenomenon became generally denominated a "crisis." See, e.g., Malpractice Nightmare, TIME, Mar. 24, 1975, at 62-63. See also Rubsamen, Medical Malpractice. Scientific Am., Aug. 1976, at 18-23. The judicial recognition of a "crisis" has been even more delayed and qualified, but courts too have more recently recognized an "alleged 'medical malpractice insurance crisis"." See Jones v. State Bd. of Med., 97 Idaho 59, 555 P.2d 399, cert. denied, 431 U.S. 914 (1977).

${ }^{3}$ Although the statutory results vary in every detail from state to state, every legislature has undertaken a review of the alleged "crisis." For a good summary review of these statutes, see White \& McKenna, Constitutionality of Recent Malpractice Legislation, 12 ForuM 312 (1977).

- Norton, Development of an Interdisciplinary Program of Instruction in Medicine and Law, 46 J. MED. EDUC. 405, 408 (1971).

3 The fact that physicians and lawyers must learn to understand that they have constructed 
The failure of doctors and lawyers to understand one another will result in more than discomfort at the country club. As health policy moves away from the private sphere and becomes a matter of greater public concern-to Congress, the federal bureaucracy, state legislatures, and the courts-it will be important for the protagonists (and their adversaries) to be able to talk with each other. Beyond this, it will be difficult for attorneys to provide adequate legal consultation to those whose profession they do not understand, or, worse still, affirmatively misunderstand. Finally, patients may suffer significant and irreparable harm at the hands of physicians who do not understand substantive law, and do not understand how it is applied. A physician who does not know how the courts will evaluate his decision to cease the treatment of a severely defective newborn is likely to inflict tremendous amounts of anguish and economic pain on the child's family. ${ }^{6}$ Similarly, it may be that physicians will continue to drive by those lying seriously injured on the side of the highway until they realize just what a "Good Samaritan" law is, and why no physician rendering aid under such circumstances will ever be found liable for malpractice in an American court. ${ }^{7}$

\section{THE ROLE OF PROFESSIONAL EDUCATION}

To the extent that the medical-legal professional misunderstanding transcends the conflicting financial interests of those in the professions-that is, to the extent it predates the perceived malpractice insurance "crisis," and to the extent that it will succeed it-it is a natural product of the professional education afforded to both physicians and lawyers. As Dr. Norton discovered in his first

\footnotetext{
very different roles for themselves has been recognized by physicians who have undertaken the training of law students, Norton, Id., as well as by lawyers who have been engaged in teaching physicians, Annas; Law' and Medicine: Myths and Realities in the Medical School Classroom, 1 AM. J.L. \& MED. 195 (1975). See also Gibson \& Schwartz, Physicians and Lawyers: Science, Art, and Confict, 6 AM. J.L. \& MED. 173 (1980).

- The awful consequences of the failure to understand fundamental legal principles that apply in this area may be quite common. They are most dramatically illustrated in Stinson \& Stinson, On the Death of a Baby, ATLANTic, July, 1979, at 64.

7 There is no reported case in which a physician was found liable for professional negligence in an action arising out of such conduct. For a further discussion of this issue and others in which a physician's ignorance of the law may give rise to inadequate medical care, see Annas, supra note 5, at 197-200.
} 
attempt to have law students and medical students talk with one another: "The first pitfall involves the basic differences in medical and legal education, such as techniques of teaching and learning, involving different thought processes and systems of logic."8 Given the epistemologies of the professions, it is not surprising that they train their students and socialize their young co-professionals in extraordinarily different ways. From the first day of law school, the law student confronts the Socratic method of instruction. The teacher seeks arguments for every position, and the best of teachers are able to help their students discover flaws in the best arguments that can be presented. There never is an answer; there are only more questions and more arguments. If it appears that a "best" argument has prevailed, that is only because class time expired before a better argument could be articulated. It is accepted dogma among law teachers that the substance of a law course is never as significant as the process by which it is communicated. Although the Socratic method of instruction has been under some criticism ever since it was initiated at Harvard Law School a century ago, it still presents the basic model for every first-year course, and most other courses offered by the vast majority of law schools in this country..$^{9}$ Only over the past few years has the development of a clinical curriculum in some law schools offered an alternative teaching technique to the Socratic method.

It is not surprising that the products of this legal education should have trouble talking with those trained at a medical school. Medical education has traditionally consisted of two years of basic science training, followed by several years of clinical training. The clinical training has traditionally been divided into a "medical student" era and an "intern and resident" era. ${ }^{10}$ During the basic sciences portion of the professional education, an aspiring physician learns of the truth which has been derived from nature. It is

\footnotetext{
Norton, supra note 4, at 408 .

- There are many reasons for the ascendancy of this pedagogy in law schools. Although some legal educators have called for its elimination (or, at least, the reduction of its application), the fact that it is used in virtually every law school is indicative of its effectiveness in attaining some very generally accepted purposes of legal education. See Boyer \& Cramton, American Legal Education: An Agenda for Research and Reform, 59 Cornell L. Rev. 221 (1974).

10 Throughout this analysis the physician's "clinical training" and "clinical medical education" refer to both the medical student portion of the training and the subsequent years of internship and residency.
} 
hardly the role of the medical student to challenge these truths, and the education is not provided in such a way that the challenge could become a part of the professional role of the physician. A first-year medical student can easily employ the memorization skills developed as an undergraduate; the law student spends his first year learning that he can never again employ those skills.

Although the subsequent clinical medical training is far different from the basic science portion of the curriculum, even that training recognizes the existence of a proper course of treatment and the existence of correct answers to medical questions. Students still gather the truth by watching a professionally and technically able faculty member administer the proper medical treatment. Although subtle challenges to the teacher's conduct may be tolerable, those challenges to apparent truths do not form the basis of medical education, as they do in legal education.

While doctors and lawyers are learning to think in very different ways, they are learning scarcely anything about each other. A law student can easily graduate without knowing anything about the medical aspects of law practice, and a physician can pass through his internship and residency without ever having confronted a legal question. Neither doctors nor lawyers need know anything about the intersection of law and medicine in order to be licensed to practice their own profession. This is merely unfortunate for law students, who may have occasion to work with medical experts and to advise physicians during the course of their practice. It is disastrous for physicians who will certainly be dealing with medical-legal problems during the course of their practice.

There is essentially unanimous agreement among medical educators that studies in the legal aspects of medical practice ought to be included in the medical curriculum. Over a decade ago the Committee on Medicolegal Problems of the American Medical Association recommended "that a course in medical law be included as a part of the curriculum of every medical school," $"$ and there is some evidence that even the malpractice "crisis" would be less significant, because malpractice rates would be lower, if the

"For an account of the development and intended impact of this recommendation, see Fisher, Teaching Medical Law, J.A.M.A., Sept. 16, 1968 at 245. 
law were a part of an undergraduate medical education. ${ }^{12}$ When British scholars were asked by the Secretary's Commission on Medical Malpractice why the "crisis" had arisen in this country, but not in England, they concluded:

\begin{abstract}
We also believe that more attention should be paid to the teaching of legal medicine both to undergraduates and to post-graduates. . . . Before embarking upon their professional careers, practitioners must appreciate their legal obligations to patients, and their relationship with lawyers. We do not believe that sufficient instruction is given to practitioners on medico-legal matters. We are of the opinion that much more consideration should be given to legal medicine in medical and dental education than is at present the case. ${ }^{13}$
\end{abstract}

Given this background, it is especially surprising that legal education in American medical schools has remained unchanged in the modern era. The notion that the relationship of law and medicine is an academically significant one is not new. Dr. Benjamin Rush, the nation's first Surgeon General and a signatory of the Declaration of Independence, published his lecture on forensic medicine, which was delivered to medical students at the University of Pennsylvania, in $1811 . .^{14}$ Several treatises on the subject appeared in this country during the next century and a half, ${ }^{15}$ and by 1931 a medical

\footnotetext{
12 "There were 22 medical schools in the 10 states with the highest malpractice insurance premiums charged physicians in 1969. Of these, only 9 schools offer courses in legal medicine. In contrast, six of the eight schools in' the 10 states with the lowest current rates offer such courses." Dornette, Interdisciplinary Education in Medicine and Law in American Medical Colleges, 46 J. MED. Educ. 389, 398 n. (1971). Of course, this is hardly a scientific sampling, and Dr. Dornette did not offer this finding as proof of any particular proposition, but rather suggestive of a valuable line of inquiry. Unfortunately, no one has undertaken the full study he suggests. In proposing a medical-legal curriculum for a medical school twenty years ago, another medical educator recognized that "malpractice in recent years has become a significant stumbling block for many doctors, and, in a sense, for the total medical profession. There is no indication this will relent of its own accord; therefore, the big avenue for cure is prevention." That prevention, he suggests, can come in the form of an integrated medical-legal curriculum. Mills, Forensic Education in Medical Schools: The Necessity of an Interdisciplinary Approach, $36 \mathrm{~J}$. MED. EDUC. 188 (1961).

13 Addison \& Baylis, The Malpractice Problem in Great Britain, in DHEW, No. 73-88 (O.S.), Medical Malpractice: Report of the Secretary's Commission on MediCAL MALPRACTICE 854, 870 app., quoted in Annas, supra note 5, at 201 n.11.

14 Lecture XVI, On the Study of Medical Jurisprudence (Nov. 5, 1810), reprinted in B. Rush, Sixteen InTRoductory Lectures to Courses Upon the Institutes and Practice of Medicine 363-395 (1899) (primarily discussing mental disease, homicide, and capital punishment).

is See Domette, supra note 12, at 400 (References 5-8).
} 
school was offering a full course in legal medicine. ${ }^{16} \mathrm{~A}$ half century ago, when the first survey of medical school catalogs was undertaken, 58 percent indicated some kind of instruction in law and medicine. ${ }^{17}$ A 1952 Report of the Subcommittee on Education of the A.M.A. Committee on Medicolegal Problems which surveyed 72 medical colleges in the United States, found that " 16 [of the responding] medical schools provide undergraduate instruction which, on the basis of current standards, appears to be satisfactory." 18 Each of the other medical schools offered a less than satisfactory curriculum. Two surveys conducted in 1970 show that about half of the medical schools responding to a questionnaire offered some form of instruction in law and medicine. One survey discovered that 42 schools out of 79 which responded to the questionnaire ( 53.2 percent) offered a formal course in the subject, ${ }^{19}$ while 47 out of 85 (55.3 percent) in the other survey indicated that they provided some form of medical-legal instruction. ${ }^{20}$ In 1973 yet another survey, this one conducted by reviewing medical school catalogs and responses to inquiries sent to medical colleges, discovered that 70 medical schools out of 116 responding $(60.3$ percent) claimed that they provided their students a course of instruction in law and medicine. ${ }^{21}$ In the most recent research in this expanding genre, a 1978 survey of medical schools revealed that 40 of 101 responding colleges ( 39.6 percent) reported that they required their students to take some courses in legal medicine,

${ }^{16}$ Levinson \& Muehlberger, An Introductory Course in Legal Medicine for Medical Students, 9 J.A. AM. MED. C. 293 (1934). This account of teaching a medical-legal course to medical students at the University of Illinois College of Medicine makes the observation that "[a]lthough legal medicine has been included in the medical curriculum of European universities for more than a century, it has been neglected almost entirely in the majority of medical schools in this country." Id.

17 Id.

1 Regan, Report of Committee on Medico-legal Problems 150 J.A.M.A. 716 (1952). For a good brief general history of the development of the medical-legal curriculum in American medical colleges, see Dornette, supra note 12.

19 Beresford, The Teaching of Legal Medicine in Medical Schools in the United States, $46 \mathrm{~J}$. MED. EDUC. 401 (1971).

20 Dornette, supra note 12 , at 391 . Of the 47 which offered some instruction, 39 offered it as a separate course or seminar. Id. at 392.

${ }^{21}$ Hirsch, Educational Opponunities in Forensic or Legal Medicine in Medical Schools, Phi Delta Epsilon News, Winter, 1973, at 2. A review of several surveys conducted over the past 20 years is found in LeBlang, Law and Medicine: A Model Academic Program at Southern llinois University School of Medicine, 1 J. LEGAL MED. 1 (1979). 
while 28 ( 27.8 percent) indicated they had no elective or required offerings on the subject. ${ }^{22}$ Although the reporting mechanisms and the survey instruments that were employed in this long history of research on medical-legal courses in medical school are very different, and although the results are not scientifically comparable, they do indicate that the development of formal course work in legal medicine for medical students has been slow. Indeed, the interest in determining how many schools offer such courses appears to far outstrip the interest of the medical schools in actually offering the courses.

This reluctance to add legal programming to the course of study of medical undergraduates has several causes. One of them may be an honest recognition by the medical schools that haphazard teaching of the law by unqualified faculty who may themselves not fully understand the subject has the effect of increasing rather than decreasing professional misconceptions and the consequent professional alienation. When a law and medicine course is taught by a physician worried by an inflated fear of malpractice liability, or by a hospital counsel whose primary function is to avoid placing the hospital at any financial risk, it is not surprising that the main subject discussed is medical malpractice, and the primary lesson doctors learn about lawyers is to avoid them. Physicians learn nothing about the legal process in such courses; in fact, the misunderstandings created by such courses make it far more difficult for doctors to learn anything about that process in the future. The message of these unfortunate medicallegal courses is that the law is an artificial construct designed by lawyers and developed primarily to serve their own financial and egocentric purposes. At best, the aspiring physicians may conclude that the law is a nuisance which interferes with their patients. At worst, physicians are trained to view attorneys as adversaries trained to extract their livelihood from well-intentioned doctors who spend more time on the care of their patients and less on some undefined bureaucratic requirements.

The low status assigned to medical-legal education in the medical school curriculum is reflected in the methods employed to teach it. Most often it is taught through a lecture or a series of

22 Grumet, Legal Medicine in the Medical Schools: A Survey of the State of the Art. $54 \mathrm{~J}$. MED. EDUC. 755 (1979). 
lectures, or, at best, in a seminar setting. Law is rarely taught to doctors the way that it is always taught to lawyers. Learning to "think like a lawyer" is the primary product of law school. It is distressing that medical students are never exposed to this reasoning process which is so fundamental to the legal profession.

Not only do medical schools avoid law school teaching methods in presenting the medical-legal courses, but they even neglect the most basic medical school teaching technique, leaving the medical-legal curriculum in a separate pedagogical category, apparently not worthy of real academic treatment. Most subjects which bear a close relationship to the physician's day-to-day contact with patients receive their serious treatment in the clinical years of medical education. Yet, there has been no development of any clinical program in law and medicine.

Aspiring physicians and embryonic lawyers both learn about their own disciplines by studying individual cases. Although the socratic case method of the law school is different from the clinical case method of the medical school, either could be used as a teaching format in a good medical-legal course. It is pedagogically unsound to teach law to medical students in a way in which it would not be taught to law students. It is academically unsound to teach law to medical students in a way in which nothing else is taught to medical students; such action only communicates to the students the medical profession's bias that the subject of the law is mysterious, unimportant, and not related to the professional role of the physician.

\section{REQUIREMENTS OF A PROPER LEGAL-MEDICAL CURRICULUM IN THE MEDICAL SCHOOL}

One reason medical schools have had such a difficult time determining what kinds of legal issues ought to be included in the medical curriculum, and how law ought to be taught, is that little analysis has been directed to why physicians need to know about the law. Until recently the medical-legal community did little to organize their discipline. The only formal division of the subject that has been generally accepted is the distinction between the very different fields of forensic medicine (essentially the impact of medicine on legal practice) and medical jurisprudence (essentially the 
impact of law on medical practice). ${ }^{23}$ A large number of writers have suggested lists of topics which ought to be included in any medical-legal curriculum, and 44 topics can be gleaned from the recommended medical-legal curriculum developed by the American College of Legal Medicine Task Force on Medical Legal Curriculum. ${ }^{24}$ As I have attempted to show, the particular substantive areas of study are not as significant as training in legal methods. Although young physicians do not need to be trained to "think like lawyers," they ought to be trained to have some idea of the way the lawyers are thinking. A physician's ability to work with a lawyer will be more enhanced by his recognition of the lawyer's method of analysis than it will by his memory of a paragraph of the state's medical reporting statute. A physician will be more willing to work with a lawyer if he understands what the role of an attorney is, and what the limitations of that role must be. Physicians need not be trained to resolve legal problems-that is, after all, within the realm of the attorneys, but physicians must be trained to recognize those problems.

The fact that the medical-legal pedagogy may be more important than its substance does not mean that such a curriculum ought to be without substance. The many subjects which have been suggested as appropriate for such a course can generally be divided into four substantive areas. The first is the physician's medical relationship with his patient, and includes the issues of confidentiality, informed consent, professional liability, and patients' rights. The second is the physician's relationship with medical institutions. This area of study includes the study of the PSRO, staff privileges, the law of institutional review boards, hospital accredi-

${ }^{23}$ The distinction is explained in Dornette, supra note 12, at 389. An earlier recognition of this organization of the discipline, and a chart comparing medical and lay dictionary definitions of these terms can be found in Levinson \& Muehlberger, supra note 16, at 293, 294, esp. 294 (Table 1). For an earlier effort distinguishing forensic medicine from medical jurisprudence, see M. Witthaus \& T. BeCkER, Medical JuRisprudenCE, Forensic MEDICINE AND TOXICOLOGY (1909). In 1823, in the first text co-authored by a doctor and a lawyer, "medical jurisprudence" was divided into "forensic medicine" and "medical police." J. Paris \& J. Fonblanque, Medical Jurisprudence i-ii (1823).

24 These topics are listed in Grumet, supra note 22, at 757. For other lists of possible topics, see LeBlang, supra note 21, at 2; Dietz, Clinical Approaches to Teaching Legal Medicine 10 Physicians: Medicolegal Emergencies and Consultations, 2 AM. J. LAW \& MED. 133 (1976); 1977-78 AAMC Curriculum Directory (1977); Dornette, supra note 12 (esp. at 400, references 3, 9, 12, 15, 19 and 20); Annas, supra note 5, at 197. 
tation, staff member relationships, and other similar subjects. The third area is the study of the business of the practice of medicine. The subjects within this area include many of those that would be of interest to any tradesman-such as billing and bill collection process-as well as some which are unique to the practice of medicine, such as the allocation of health care costs to governmental and other sources.

Finally, there is a group of subjects which involve the physician's relationship to legal and political institutions. These may include the study of licensing processes, civil commitment procedures, forensic pathology, and child abuse statutes. They must also include a study of the physician's role in creating and altering social power. The physician has a professional duty to participate in the drafting of public health legislation, health financing regulations, mental health law, hospital accreditation standards, and appropriate rules of evidence, just to name a few areas of special concern. Perhaps because we have been so reluctant to recognize this part of the professional physician's role, medical-legal curricula have only rarely included this fourth area, and they have not been designed to train physicians to participate formally, and at a stage when it will make a difference, in these social policy debates. ${ }^{25}$

Although some legal issues will be of greater import to physicians in a particular specialty, legal medicine cannot be left to those who choose to practice it as one would choose a specialty. Legal questions arise in every part of the practice of medicine, and every physician has an obligation to participate in the formulation of public policy. ${ }^{26}$ Thus, just as every physician must have enough training in hematology to be able to know when to call in a specialist to help diagnose a blood disorder, every physician ought to have enough training in law and the legal process to know when to call in an attorney to help diagnose a legal problem.

Meeting these goals of a medical-legal curriculum will require bringing physicians and lawyers together, to study medical-legal problems in context, as they arise, and not as purely academic subjects. There are several ways of bringing law students and

2s The degree to which this part of the curriculum is slighted is demonstrated by its virtual absence from the list compiled in Grumet, supra note 22, at 757.

${ }^{26}$ For an account of the way the medical profession generally sees the "specialty" of legal medicine, see Dietz, supra note 24, at 135. 
medical students together in a manner that will allow them to watch professionals with whom they are unfamiliar practice their discipline. Seminars which include both law and medical students will at least provide each with an opportunity to talk with the other. Field trips may dissolve the mystery of the trial for a physician, or the awesomeness of surgery for a law student. Encouraging law and medical students to do research together will force them to do logically consistent analysis, and this will require that they each understand the premises and the logic of the others' argument. Where this has been tried, it has been a remarkable success and has resulted in research with immediate impact upon the legal and medical communities. ${ }^{27} \mathrm{~A}$ formal paper logically and substantively acceptable to both a physician and a lawyer is likely to have a significant impact on its authors as well as its readers.

Even in the absence of a formal and integrated course, aspiring physicians (as well as young lawyers) can have an opportunity to see medical-legal problems in context. For example, mock trials may be helpful in developing an understanding of the legal process-especially to physicians who may be familiar with the medical situation which gave rise to the legal action. ${ }^{28}$ Integrating legal problems into the medical curriculum, and especially the clinical curriculum, is likely to give medical students some understanding of the application of the law to medical practice. ${ }^{29}$ The use of hypotheticals, taken from a medical clinic or a court's docket may impress upon physicians the absolute necessity of dealing with particular legal issues. ${ }^{30}$

${ }^{27}$ Several examples of the kinds of joint medical-legal research likely to have an impact on both professional communities can be found in Norton, supra note 4, at 407-408.

28 An especially good mock trial program is described in LeBlang, supra note 21.

29 See Mills, supra note 12.

${ }^{30}$ The use of hypotheticals to train physicians to deal with medical-legal emergencies was suggested by Dr. Dietz in an article which also recommended the creation of something like a consultation service in legal medicine. He suggests the following hypotheticals:

1. The bereaved parents of a boy who has just died of a gunshot wound insist on taking immediate custody of the body.

2. A police detective insists that a surgeon surrender a bullet he has just semoved from a patient's abdomen.

3. An adolescent female states that she has just been raped and desires medical attention, but asks that the police not be notified.

4. A psychotic patient signs a release of information form prepared by his wife's attorney, not appreciating that his medical records document multiple acts of adultery. 
The pedagogical method used in teaching legal medicine may determine where in the course of the curriculum it ought to be placed. If it is relegated to the first two years, which are generally characterized by a lecture teaching method, it is likely to be too academic and unconnected with practice for the medical students to consider it significant. If it does not appear until the very end of the medical school curriculum, the students are likely to have already decided which subjects are important, and they are unlikely to be receptive to an entirely new subject. Given the need to bring medical and law students together, and the need to present medical-legal problems in context, it may be most appropriate to start a formal program during the first part of a medical student's clinical training. Although legal medicine should not be a separate clinical rotation, medical students ought to be taught when and how to interact with or employ attorneys as soon as they begin engaging in the kind of patient contact that characterizes their profession. Just as they will have medical specialists available to them during their clinical practice, they ought always to have attorneys available for consultation during this time.

\section{MEDICINE IN THE LAW SCHOOL CURRICULUM}

Just as medical-legal problems have been the subject of pedagogically unsound programs in the medical schools, they have been the subject of inadequate curricula in the law schools. Courses in law and medicine have been treated as if they were logically indistinguishable from any other substantive course offered by the law school, and the leading texts are designed to comfort the traditional Socratic teacher. ${ }^{31}$ But just as medical

5. A paranoid schizophrenic who insists on going home hears voices telling him to kill a neighbor whom he believes is persecuting him.

6. A middle-aged Jehovah's Witness requires emergency treatment for severe bleeding, but refuses to permit a blood transfusion.

7. An injured child requires immediate surgery and no relative can be located to consent to the procedure.

8. A prominent businessman contracts syphilis and threatens to sue the physician if he reports the case to the public health authorities.

Dietz, supra note 24, at 140-141.

31 There are three law school textbooks designed for use in law and medicine courses: Curran \& Shapiro, Law, Medicine, and Forensic Science (2d ed. 1970); Sharpe, 
students must learn to do legal analysis, law students ought to be exposed to the circumstances under which physicians confront medical-legal problems. Law students must develop some notion of a Baconian theory of knowledge and the scientific method that forms the logical arsenal of the physician. The law student must recognize that doctors' decisions sometimes must be made without the benefit of reflection and research, and in a manner which does not permit the application of a Socratic model.

Thus, in the law school curriculum as well as the medical school curriculum, a course in law and medicine must be designed to bring doctors and lawyers together, and to present medical-legal problems in the contexts in which they arise. It should be easier to do this in the law school curriculum than in the medical school curriculum for two reasons. First, while all physicians ought to be exposed to a wide range of medical-legal problems, not all lawyers need that same exposure. While all physicians will deal with legal issues, not all attorneys deal with medical issues. Thus, the medical-legal course at a law school may be directed to only a small group of students who are particularly interested in the subject. Second, the flexibility of the law school curriculum-there are rarely required courses after the first year-ought to make it easier to integrate a course which meets the goals outlined above.

On the other hand, the narrow limitation on the range of acceptable pedagogical devices generally employed in law teaching may make it difficult to design a course acceptable to law school curriculum committees and yet accessible to non-lawyers. While neither the pure Socratic course nor the lecture course is especially suited to bringing medical and legal professionals together to evaluate particular medical-legal problems, the rapidly developing clinical curriculum of many law schools is particularly appropriate to this end. ${ }^{32}$

\section{THE LAW-MEDICINE CLINIC}

Both the law school and medical school curricular needs for a medical-legal course could be met by a joint clinic sponsored by the two schools. In such a clinic, law students, under the close super-

Fiscina, \& Head, Cases \& Materials on law and Medicine (1979); Wadlington, Waltz, \& Dworkin, Cases \& Materials on law and Medicine (1980).

32 For a history of the development of clinical legal education, see Barnhizer, Clinical 
vision of the faculty or a competent attorney, would regularly be available for consultation by medical students, interns, residents, and attending physicians at the medical school. Just as law students in other clinics represent defendants in criminal actions, participants in administrative hearings or prisoners, law students in a medical-legal clinic would represent physicians or medical students performing essentially the role of physicians. They would schedule regular office hours, and be available to respond to particular inquiries during that time. They would also be available to prepare general memoranda for the physicians' or the hospital's use, to cenduct formal or informal negotiations, to prepare the physicians for participation as witnesses in litigation, and, where appropriate, to represent the physician or the hospital in active litigation. In addition, the law students in such a clinic could prepare and deliver "legal rounds" on legal issues of general concern at the medical school.

The law students in the medical-legal clinic could provide their services to one particular department or rotation, or to a larger division, or the medical school as a whole. When a physician is faced with a pregnant teenager who wants an abortion without her parents' knowledge, or a person in the emergency room who does not want the fact that he has been drinking noted in his medical record, he can seek out the student lawyer for assistance. Similarly, if a doctor were to prepare testimony for a legislative committee on the necessity of strict fireworks ordinances, or the value of a particular commitment process, he could seek legal assistance from the law clinic. The students could also provide legal counsel to a medical school admissions or student retention committee, and to the institutional review board. Since such legal advice is now often not easily available to the medical school, the law clinic would not be duplicating the work of other attorneys, and because all of the student work would be done under the direct supervision of a competent attorney, the legal work ought to be of adequate quality. Indeed, experience with student law clinics has shown that the quality of student work is often superior to that which would be offered by practicing attorneys if there were no clinic. ${ }^{33}$

Education at the Crossroads: The Need for Direction 1977 B.Y.U. L. REv. 1025. For a good explanation of the operation of a legal clinic, see Meltsner \& Schrag, Essay: Scenes from a Clinic, 127 U. PA. L. Rev. 1 (1978).

${ }^{33}$ For example, a New York University School of Law committee established to evaluate 
The development of this law-medicine clinic would have several pedagogical advantages over the current methods for teaching law and medicine in both law schools and medical schools. This joint clinic would bring prospective physicians and attorneys together to discuss cases in the contexts in which they actually arise. Doctors and medical students would recognize the uncertainty of the law, and they would be able to work with law students and lawyers in applying the legal process to a legal problem. Law students, on the other hand, would have an opportunity to see the circumstances under which physicians must make legal determinations, and the speed with which life and death questions must be resolved.

The clinic would also provide young physicians and medical students with practice in the role of legal clients. This is one of the few professional roles which medical students cannot otherwise practice during their years of clinical medical training. Medical students ought to recognize what kinds of problems are susceptible to legal advice, and what natural limitations exist on the utility of the law in resolving day-to-day problems. In short, doctors will discover how to employ lawyers efficiently.

This law-medicine clinic will also deal with substantive legal issues in a manner that both law schools and medical schools have found to offer superior pedagogy-the use of the clinical setting. This setting is one particularly familiar to medical schools, and one which is becoming widely acceptable in law schools. ${ }^{34}$ Finally, because the law-medicine clinic would bring together emerging professionals in their professional roles, it would be likely to create a respect for the legal profession by physicians as well as a respect for the medical profession by lawyers.

There are problems which must be resolved before such a clinic can be installed as part of the law school and medical school curriculum. First, any such program would have to carefully define

that school's clinical offerings concluded that "our clinics and their instructors have established a reputation for professional competence which cannot but benefit the over-all reputation of the school." Report of the Special Committee on Clinical Programs, New York University School of Law (April 29, 1976). Judges who have investigated student practice apparently agree. The Final Report of the Committee to Consider Standards for Admission to Practice in the Federal Courts to the Judicial Conference of the United States (the Devitt Committee Report), (1979), recommends that student practice in the federal courts be expanded. Devilt Committee Report, Sec. III B(4), at 17-18.

34 See Bamhizer, supra note 32. 
the law students' clients. If the physician is personally the client of the law clinic, the student attorney and his supervisor face several potential conflicts of interest. For example, if the physician is, or might be, in a position adverse to hospital administration, could he still be represented by a student in a clinic otherwise representing the hospital itself? Can the student lawyer offer his services to an institutional review board or hospital privileges committee which someday may evaluate a proposal by the physician-client?

Second, before a law-medicine clinic is established, the relationship of the student attorney and his client's patients must be established. Is the attorney in a special relationship with his client only, or is he a part of the "treatment team" which has a medical obligation to the patient? Must ihe patient be told of the lawyer's presence? Should the lawyer have access to the patient's medical records, and under what circumstances ought these records be made available? If the lawyer is in a fiduciary relationship with his physician client and the physician is in a fiduciary relationship with his patient, is a lawyer/patient relationship necessarily created? For example, what would a student lawyer's obligation be upon his discovery that his client, a physician, had enticed a patient into serving as a subject in a legally questionable experiment? Finally, if the patient had any authority to limit the attorney's activities on behalf of the physician, would that impinge upon the lawyer/client relationship and the legal protection accorded it?

Of course, these problems arise whenever an attorney undertakes the representation of a whole medical service. There is another problem which is inherent in any medical or legal clinic which is designed both to train students and to provide services. The best pedagogy does not always provide the best service; sometimes one must be sacrificed to the other. In the case of a law-medicine clinic, the conflict could arise among the educational needs of the law student, the educational needs of the medical student, the medical needs of the patients, and the legal needs of the physician.

None of these problems is insurmountable. In fact, the first group of problems have been resolved by attorneys who represent hospitals and medical schools, and the inherent problems of every clinical training scheme have been surmounted in law clinics and medical clinics around the country. Indeed, the discussion that would arise out of a meeting of physicians and lawyers to resolve 
just these questions might provide real insight for members of each profession into the goals, ethics, and the reasoning processes of each profession. Thus, just the attempt to establish this lawmedicine curriculum may provide law schools and medical schools with the recognition of the importance of such a program, and with an example of the good which can come out of it.

\section{CONCLUSION}

The discomfort doctors and lawyers feel with one another is not a consequence of the perceived medical malpractice crisis or any other single area of substantive disagreement. Rather, it is a reflection of the different epistemologies of the professions. The truth seeking activities of the two professions are very different, and these differences are reflected in the widely divergent professional educations provided to medical and law students. Much of the animosity which has developed between doctors and lawyers could be avoided, and members of each profession could have a much better understanding of the substance and analytic methods of the other discipline if law students and medical students were brought together to study medical-legal problems which arise in the context of active practice. Unfortunately, with only a few exceptions, neither medical students nor law students are currently offered medical-legal courses taught in ways reasonably calculated to provide them with the background they need. The development of a law-medicine clinic in which law students, under careful supervision, could counsel and represent medical students, interns, and residents would provide a particularly appropriate way of meeting the goals that have been established for a medical-legal course, both in the law school and in the medical school. 
$\therefore$ 